\title{
Some Recently Rediscovered Analyses of Chinese Bronzes from Oxford
}

\author{
A.M. Pollard, J. Rawson, R. Liu \\ Research Laboratory for Archaeology and the History of Art, \\ School of Archaeology, University of Oxford
}

\begin{abstract}
We report here the rediscovery of the chemical analyses of approximately 540 Chinese bronze objects, carried out in RLAHA in the late 1950s by optical emission spectrometry. Although largely of historical interest, they do in fact even now approximately double the number analyses of Chinese bronze objects which contain data on both major and minor elements. In fact, the other major equivalent data set from the Freer Gallery and the Sackler Collection are of approximately the same vintage. We attempt to evaluate the quality of the data, and address a controversy which appeared in the literature during the 1960s and 1970s about the value of arsenic measurements in Chinese bronzes as an indicator of authenticity.
\end{abstract}

In the late 1950's, the Research Laboratory for Archaeology and the History of Art, University of Oxford, undertook several large programmes of chemical analysis of archaeological bronze objects. This resulted in the publication of a large corpus of British Middle and Late Bronze Age analyses (Brown and Blin-Stoyle, 1959) in the Proceedings of the Prehistoric Society. This paper, together with a complete table of 438 analyses, was also published in volume 2 of Archaeometry (page 60: 'Analysis of British Middle and Late Bronze Age material using optical emission' (anon.), and supplement, page 1 'Chemical composition of the bronzes', by A. E. Blin-Stoyle). The note on page 60 states that 'More than a thousand analyses of bronzes have now been made in the laboratory by this method' (i.e., optical emission). The missing analyses were probably those resulting from a programme of analyses of Chinese bronzes from the British Museum, the Victoria and Albert Museum, the Museum of Eastern Art, Oxford (now the Ashmolean Museum), and the University Museum, Cambridge, which appear never to have been published This is despite being much-anticipated in the literature of the time. Barnard (1961) compiled all the chemical data on Chinese bronzes known to him (approximately 389), and states that, referring to the 
forthcoming publication: 'this.... survey will cover considerably more materials than those presented in the following pages: 35 bronzes in the Freer Gallery of Art, 400 spectrographic analyses recently completed at Oxford comprising mainly bronzes in the Ingram collection, ...' (Barnard 1961: 169). The data from the Freer Gallery was published in Pope et al. (1967) and Gettens (1969: 48-53), consisting of 97 measurements on major elements (Cu, Sn, $\mathrm{Pb}$ ) by wet chemistry, and 'semiquantitative' analysis of trace elements (Ag, Au, Fe, Co, Ni, As, Sb, Bi, Zn and $\mathrm{Si}$ ) by optical emission spectroscopy. The only comparable data subsequently published in the West is contained in the two major volumes on Shang and Zhou bronzes from the Sackler collection (Bagley, 1987; Rawson, 1990), which also includes lead isotope measurements. The fact that the Oxford data had not been published by 1975 is confirmed by further comments in Barnard and Tamotsu: 'then, of course, there remains the considerable gap of data (still unpublished) comprising the "400 Oxford analyses” , (Barnard and Tamotsu, 1975: 20). They do, however, seem to have been in circulation, and to have formed the basis of a dispute between Barnard and a reviewer of his 1961 volume, Sir Harry Garner (Garner, 1962). In a very spikey review, Garner challenges some of the observations on chemical composition made by Barnard (in particular, the suggestion that the absence of arsenic is an indicator of authenticity for Shang bronzes - Barnard (1961: 177)), stating that 'Many of the conclusions put forward by the author are contradicted by the results of the Oxford tests', whilst noting the these analyses 'have not yet been published' (Garner, 1962: 38). He continues: 'It seems likely that the absence of arsenic in many of the analyses is the result of the inadequacy of the test methods rather than a reality'. The quality of the Oxford data is discussed further below, but this exchange shows that copies of the data must have been in circulation in the early 1960s.

The analyses were most likely carried out by Audrey Blin-Stoyle, or perhaps overseen by her but executed by R.V. Jolowicz (see below). Blin-Stoyle was involved in the analysis and publication of the British Late Bronze Age metalwork, and footnote on the paper by Brown and Blin-Stoyle (1969: 189) says that 'The preliminary work in setting up the apparatus and refining the method as well as much of the laborious calculation involved on making the analyses was done by R.V. Jolowicz with the assistance of C.C. Humphreys under the personal supervision of the Director of the Laboratory, Dr E.T. Hall'. There is nothing in the surviving notes to say why the Chinese data were not published. There is some evidence to suggest that Francis Schweizer attempted to collate the data in the early 1970s - probably as part of a larger project to recover all of the analytical data done by RLAHA to that date. The 
files on the analyses of metals were then collected by Peter Northover when Francis Schweizer left the lab, and were stored until his retirement from the Department of Materials. This is very fortunate, because the Lab moved from its original location in Keble Road in 2004, and many old records were lost at that time. The cards were returned to the lab after his retirement, but their significance was only established when reading through the works of Barnard, and it was realised that they were the 'missing analyses' from the 1950s.

The analyses of Chinese bronzes reported here were clearly put in motion by William Watson while he was at the British Museum. He moved to SOAS in the 1960's as Professor of Chinese Art and Archaeology. From the collection at the British Museum, Watson singled out groups in which he was especially interested. These included discreet groups of bronzes with reasonably good provenances: weapons, tools and ornaments from the Minusinsk basin in South Siberia, weapons and fittings from the borders of northern China and a group of bronzes, many fragmentary, from two sites of the third to second centuries BC in Yunnan (Shizhaishan and Liangwangshan). To these he added bronzes of Warring States and Han dates from Central China. To represent the earlier Central Chinese production of the Shang and Zhou, bronzes from the Ashmolean Museum were sampled, along with some from Cambridge. William Watson was also very interested in the archaistic bronzes of the Song period and later and selected items of this period and later from the Victoria and Albert Museum to be included in the project.

The records consist of a deck of approximately 4-500 handwritten file cards, one per sample, containing information on the museum of origin, a brief (non-technical) description, an estimate of the date, and the chemical analysis (reported as percentages of $\mathrm{Cu}, \mathrm{Sn}, \mathrm{Pb}, \mathrm{As}, \mathrm{Sb}$, $\mathrm{Ni}, \mathrm{Bi}, \mathrm{Fe}, \mathrm{Zn}, \mathrm{Ag}$ and $\mathrm{Au})$. Most samples are represented by duplicate cards, suggesting that there may have been two sets of records. The blank cards were pre-printed, and carry the phrase 'By spectrometric solution method. Reference: -Proceedings of Prehistoric Society '59 New Series Vol. 25 page 188' (i.e., Brown and Blin-Stoyle, 1959). These cards refer to analyses of objects from the Eastern Art Collection, Oxford (now part of the Ashmolean Museum), the University Museum, Cambridge and the Victoria and Albert Museum, plus five objects from Bluett's (oriental art dealers). Many of the cards for objects from the Victoria and Albert Museum have a small photograph of the object glued to the back, although some are now detached. Amongst the papers in files associated with these cards are lists of the objects supplied for analysis from these museums. 
The British Museum data are in a different format. They are listed on smaller cards, with ten analyses per card on one side, and a short description of each object on the back. These cards have the name 'Mr W. Watson' on them. Watson was then the Curator of Eastern Art at the British Museum, and the sample lists make it clear that the analyses were carried out with his co-operation. The elements reported here (as percentages) are $\mathrm{Cu}, \mathrm{Sn}, \mathrm{Pb}, \mathrm{As}, \mathrm{Sb}, \mathrm{Ni}, \mathrm{Bi}, \mathrm{Fe}$, Zn, Ag, Mg and Au (i.e., as above, but with the slightly inexplicable addition of magnesium, which was only reported once, as $<0.005$ ). These analyses are also hand-written, and a few appear of have a second analysis written over the top in pencil, although some of these are now illegible. This suggests that there may have been repeat analyses made on some samples.

\section{Analytical Procedure}

The analytical procedure carried out on the British Middle and Late Bronze Age material, and, by extension, on the Chinese samples, is described in Brown and Blin-Stoyle (1959: 189), and in more detail by Jolowicz (1959). The instrument used was a large Hilger quartz spectrograph, donated to the Lab by Major H.W. Hall. A schematic diagram of this specific instrument, plus some examples of the resulting photographic strips, is given in Britton and Richards (1969: 605). The sample (about 25-30 mg) was taken using a dentist's drill of diameter 0.042 inches, care being taken to remove any patina before sampling. A carefully weighed aliquot of $10 \mathrm{mg}$ of this sample was then dissolved in $0.1 \mathrm{~cm}^{3}$ concentrated nitric acid and $0.1 \mathrm{~cm}^{3}$ concentrated hydrochloric acid, and diluted with $0.2 \mathrm{~cm}^{3}$ water. The spark in the spectrograph was provided between a lower solid graphite pencil electrode and an upper hollow graphite electrode, into which the sample solution was placed. The solution was placed into the upper electrode cup, which had been pre-heated to red-heat with a blowpipe to increase the porosity. The solution seeped through the upper cup onto the spark gap to provide the emission spectrum. The spark gap was set at $3 \mathrm{~mm}$, and the spark $(12 \mathrm{kV})$ run for 10s before recording the spectrum. The photographic plate was exposed for $30 \mathrm{~s}$ for each sample, and each plate contained the spectra from one standard bronze and 17 unknown samples. The intensity of each selected emission line (and background) on the developed plate was measured using a Hilger non-recording microphotometer. 
A number of corrections were made to these readings. The sensitivity of each plate was calibrated using a spark between lead electrodes, to estimate the 'gamma' of the plate - the ratio of the increase in blackening to the increase in light intensity. Using a set of (unspecified) calibration bronzes, containing all the elements of interest, a table was produced showing the relationship between intensity and concentration for each element, as a function of plate 'gamma'. Furthermore, because the relationship between intensity and concentration is not linear over the entire range, a modified Seidal correction factor (Kaiser, 1941) was used to extend linearity. This correction was incorporated using specially-prepared logarithmic graph paper. Calibration appears to have taken the form of calculating the ratio of each element to that of the copper in the bronze, and then converting this set of ratios to an overall chemical composition. Since this calculation must have involved a normalisation procedure, it should be noted that the closeness of the analytical total to $100 \%$ cannot be taken as independent evidence of the quality of the analysis, in contrast to the case of gravimetric analysis, where the estimate of each element is independent.

\section{The Data}

The analytical data, as transcribed from the record cards, are presented in Supplementary Tables S1 to S4, and are also available as an Excel file on the RLAHA website (http://flame.arch.ox.ac.uk/public-resources/Chinese-data/), where more detail is given about the numbering of the cards.

\section{Ashmolean Museum (Table S1)}

Table S1 lists the analyses of 194 objects from the Museum of Eastern Art, Oxford, which now forms part of the collection of the Ashmolean Museum. The descriptions of the objects and the assigned dates are taken from a typed list kept in the file, which also lists several objects which appear to have no analysis (or the record cards are missing). These have been left in as blank lines on the Table to signify that they may have been sampled.

The objects all bear the accession date 1956, and all appear to be part of the Ingram collection. This gift, comprising more than 3000 Chinese and Japanese objects, was given to the Museum of Eastern Art (at that time housed in the Indian Institute, Broad St., Oxford) by Sir Herbert Ingram (1875-1958) in 1956. It was transferred to the Ashmolean Museum in 
1962, and many of the objects can be seen in the Museum's online catalogue (http://jameelcentre.ashmolean.org/collection/).

\section{British Museum (Table S2)}

Table S2 lists the analyses of 250 objects from the British Museum, as described by the handwritten notes on the back of the record cards. As noted above (and highlighted in the Table), some of the analyses, which were normally written in pen, also had a second analyses written over the first entry in pencil, which we currently interpret as being repeat analyses. Both are given in the Table, with the 'pencil' version being the second of the pair.

The file contains a typed letter from William Watson (then Assistant Keeper of Oriental Antiquities of the British Museum) to Mrs E.E. Richards at RLAHA, dated $29^{\text {th }}$ May 1959. It says: 'Here are the short descriptions of the Chinese bronzes from which you took specimens of metal', and lists 24 objects. However, from the registration numbers given, 14 of these do not appear on the data record cards, and, of those that do, five are samples which have a second set of data written in pencil. A second note, written by hand and dated $29^{\text {th }}$ June 1959 , is addressed to Mrs Blin-Stoyle, and appears to correct two of the registration numbers given on the original sheet. Unfortunately, it would appear that some of the samples analysed are not listed on any document other than the data record cards. However, many additional items from the British Museum were sampled.

\section{Victoria and Albert Museum (Table S3)}

Table S3 lists the analyses of 100 analyses of 82 objects from the Victoria and Albert Museum (objects with more than one part were analysed separately). Unlike the previous two datasets, these mostly appear to be later bronzes, from the Han dynasty onwards. A typed inventory of samples exists, giving details of these 82 objects, but unfortunately it bears no name or date, other than a hand-written heading (Victoria + Albert Museum). A further seven objects which do not appear on this list seem to have been analysed, some of which can be identified from the online catalogue. Three of the objects on the list are identified as Japanese (76-1907, 147-1876 and M.16-1934). A further small note exists, with 'To Audrey’ written in pencil in the corner, which is headed 'Bronzes in the Victoria and Albert Museum needing analysis', and lists a further 9 objects, the last of which is added by hand. 
Table S4 lists the analyses of 16 objects from the University Museum, Cambridge. One object appears to have been analysed twice, or is made from more than one component (24.987). A note exists which can be linked to these analyses by the accession numbers, but is otherwise unlabelled apart from the heading 'Chinese bronzes'. It lists 15 objects, grouped into 'genuine antiques' (5) and ‘said to be forged' (10).

\section{Value and Significance of the Analyses}

The rediscovery of these 540 chemical analyses of Chinese bronzes more than doubles the number of complete published chemical analyses (i.e., alloying elements plus significant trace elements) we have for such material. Mostly, however, the objects are without provenance. The large coherent nature of the database also allows us to explore a little more the quality of OES data of this vintage.

How reliable are these analyses? There is no specific discussion of the limits of detection in the publications referred to above, nor in the file documents. Two forms of notation are used in the data tables to signify measurements at or below the limits of detection: a dash (-) or 'nd' are used to signify measurements below the limit of detection (i.e., not detected). (Although this is not specified anywhere, I think we can be certain from the description of the methodology that these elements were sought for but not found). The second set of notation uses '<', presumably to indicate a measurement which is identifiably present but not quantifiable, which we might interpret as a simple definition of the limit of detection. Obviously, this varies from element to element, and also varies from measurement batch to measurement batch. Without detailed information about the run sequence, we can divide the data up into museum groups, since these were probably analysed at different times.

Table 1 shows the quoted mdl for each element in each group of material. Multiple rows imply that more than one value is quoted as the mdl within a particular museum group - this might reflect between batch variation, since each photographic plate only allows 17 analyses.

\begin{tabular}{|l|l|l|l|l|l|l|l|l|l|l|}
\hline MDL's & Sn & Pb & As & Sb & Ni & Bi & Fe & Zn & Ag & Au \\
\hline Ashmolean & 0.1 & & 0.01 & 0.05 & 0.01 & 0.004 & 0.006 & 0.04 & & 0.01 \\
\hline & & & 0.1 & & & & & & & \\
\hline
\end{tabular}




\begin{tabular}{|l|l|l|l|l|l|l|l|l|l|l|}
\hline BM & 0.1 & 0.02 & & 0.04 & 0.01 & 0.01 & 0.004 & 0.04 & & \\
\hline & & & & 0.05 & & & & & & \\
\hline & & & & 0.01 & & & & & & \\
\hline V\&A & 0.1 & & 0.1 & 0.05 & & 0.04 & 0.006 & 0.006 & & 0.01 \\
\hline Cambridge & & & 0.1 & 0.05 & 0.01 & & 0.006 & 0.04 & & 0.01 \\
\hline & & & & & & & & & & \\
\hline $\begin{array}{l}\text { Lowest } \\
\text { recorded } \\
\text { value }\end{array}$ & 0.01 & 0.02 & 0.037 & 0.025 & 0.0087 & 0.004 & 0.0035 & 0.054 & 0.0013 & 0.008 \\
\hline
\end{tabular}

Table 1. Estimates of lowest limits of detection in the RLAHA datasets

There are some variations in some elements, of which arsenic is the most significant. Within the Ashmolean data, it is variously quoted as ' $<0.01$ ' or ' $<0.1$ ', whereas in the rest of the data it is given as ' $<0.1$ '. Bismuth varies from 0.004 to $0.04 \%$. Another way of estimating the mdl is to record the lowest definite value given for each element, although this ignores the variation from plate to plate.

Another feature of OES data using photographic plate recording is that high levels of certain elements often cause the signal to saturate, resulting in estimates such as ' $>15 \%$ '. For archaeological bronzes, this primarily affects measurements of lead and tin, and also zinc in later objects. For the data presented here, this does not affect seem to affect the values of $\mathrm{Pb}$ and Sn reported, as they are all reported as definite values. The maximum values recorded are 22.3\% $\mathrm{Pb}$ and $30.4 \% \mathrm{Sn}$, and the averages are 5.67\% and 9.19\% respectively. Comparison with the data from the Sackler collections (discussed below) shows a maximum of $48.6 \% \mathrm{~Pb}$ on that collection (although only seven objects have more than 25\%) and 34\% Sn. Within the data on later objects from the Victoria and Albert Museum, there are a significant number (23) of high zinc values which are reported as ' $17 \%$ ', etc. This presumably reflects the fact that the experimental conditions were optimized for the analysis of $\mathrm{Cu}-\mathrm{Pb}-\mathrm{Sn}$ alloys rather than the brasses. The lowest uncertain number is $\sim 10 \%$, the highest is $\sim 25 \%$. Within the analyses of the BM samples, one value of $24 \%$ is recorded as a definite value, but one would expect some uncertainty. It is likely that the higher values of zinc on these analyses (Zn>10\%) are subject to some uncertainty.

Garner (1962) pointed out, unfairly, since the data were not published, that the Oxford results contradicted Barnard's cautiously phrased suggestion that ''attested' (i.e., genuine) bronzes contained no arsenic, whereas ‘unattested’ bronzes showed traces (Barnard, 1961). Barnard 
also pointed out that 'attested' Shang and Zhou bronzes contained no zinc. It is well-known that arsenic is one of the more difficult elements to measure, irrespective of the method used. It is a semi-metal, and has both variable valency and the tendency to form organometallic complexes. Some species are also volatile. It usually has a higher mdl than other trace elements.

Because the objects analysed in the RLAHA dataset cover a wide range of (assumed) sources and dates, as well as typologies, it is not possible to make an accurate comparison of the measured As values in these data and those in the Freer. However, the samples analysed from the Ashmolean (Museum of Eastern Art, Oxford) (Table S1) contain 55 pre-Han bronzes, and so in order to look for systematic discrepancies between the As levels recorded in the two data sets, it is reasonable to compare these with the Freer data. Figure 1 shows a histogram of the reported As distribution in these two datasets, along with the cumulative \%As. Figure 2 is a direct comparison of these two cumulative frequency distributions, along with the cumulative \%As from the Sackler Shang and Western Zhou data (the only comparable datasets on Chinese bronzes which record a similar range of trace elements)..

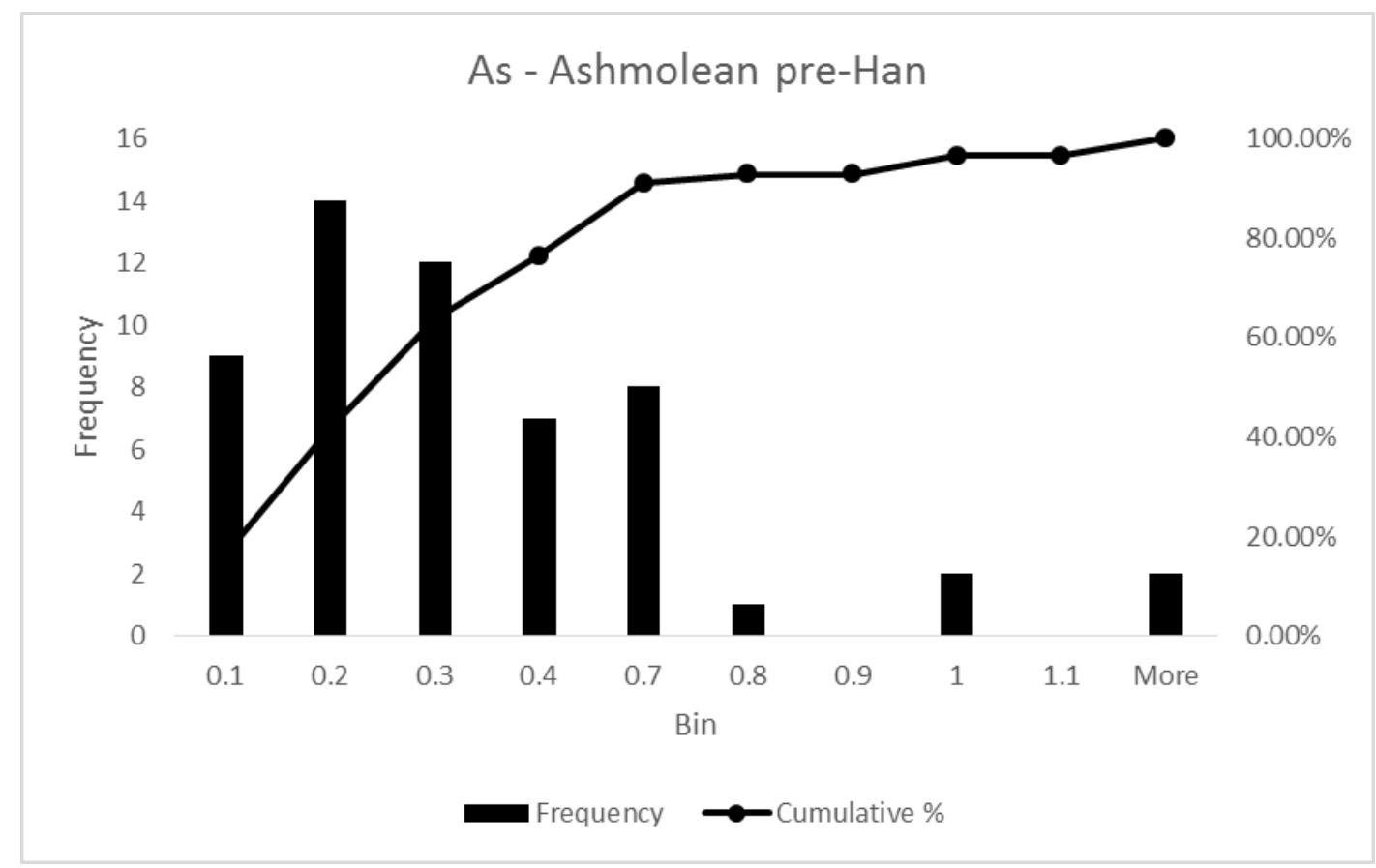




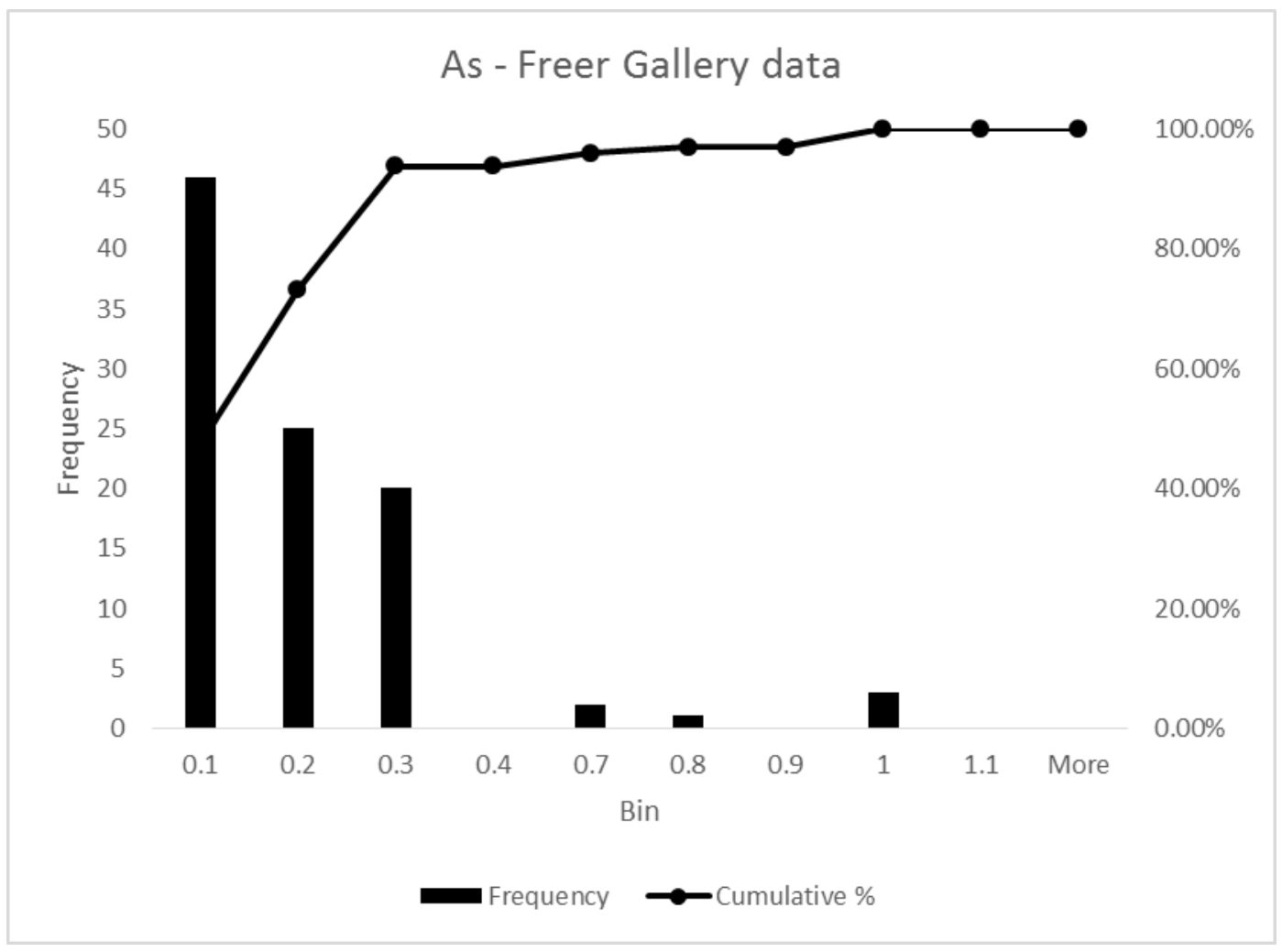

Figure 1. Histogram and cumulative frequency curve for As: (a) in the Ashmolean (RLAHA) data reported here and (b) the Freer collection (Gettens, 1969: 48-53).

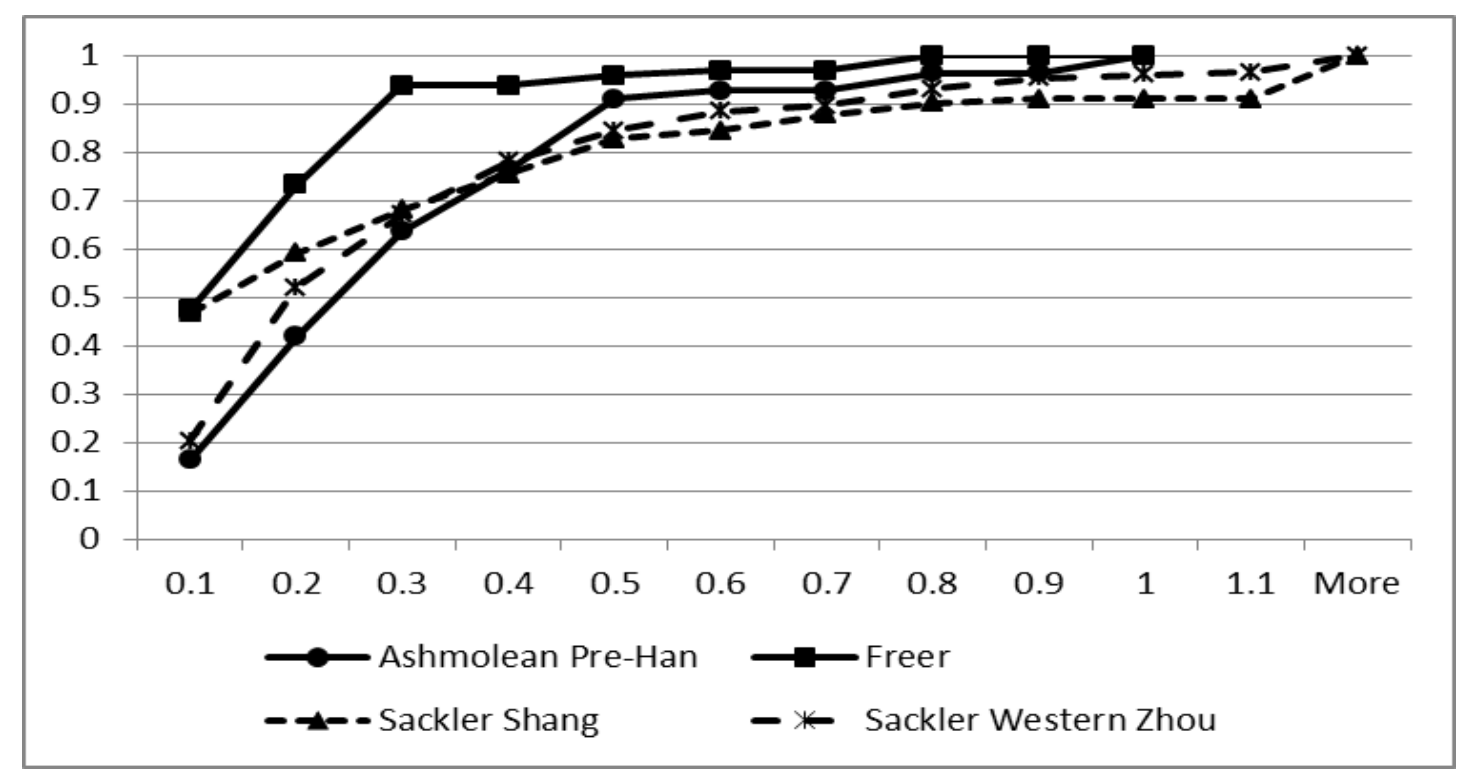

Figure 2. Comparison of cumulative frequency distributions for As in the Ashmolean (RLAHA) data, the Freer collection (Gettens, 1969), the Sackler Shang data (Bagley, 1987) and the Sackler Western Zhou collection (Rawson, 1990). 
Although the two sets are not rigorously matched, it would appear that the Freer data has a higher proportion of values in the $<0.1 \%$ bin, and the Ashmolean data are on average slightly richer in As than those of the Sackler. Using the cumulative frequency distributions shown in Figure 2, it is possible to test the difference between them using the Kolmogorov-Smirnov test statistic. This is based on the maximum difference between the two distributions for all values of $\mathrm{x}(\mathrm{D})$. The test statistic is:

$$
\text { Dcrit }=c(a) \sqrt{(n 1+n 2) / n 1 n 2}
$$

where $\mathrm{n} 1$ and $\mathrm{n} 2$ are the number of samples on each distribution, and c(a) depends on the level of confidence. For 95\% (two-tailed) it is 1.48. In this case the maximum difference between the two distributions is 0.314 and the critical value is 0.250 . Since the difference is greater than the critical value, it is unlikely that these two distributions could differ just by chance. This suggests that there might be a systematic difference between the As measurements made in Oxford and at the Freer Gallery. Comparison with the two cumulative frequency curves for the Sackler Shang and Western Zhou data shows better agreement between these two and the RLAHA Ashmolean data than with the Freer data, suggesting that the Ashmolean data may be more reliable, although this needs further work on the objects analysed from these collections to be sure that the comparison is valid. It may be, however, that Garner (1962) was correct o point out systematic differences in arsenic determinations between the two datasets available to him in the 1960s, probably due to measurement discrepencies.

\section{Conclusions}

We present a large set of chemical data from Chinese bronzes carried out in Oxford in the late 1950s, but not published. Apart from the historical impetus to (finally) publish such an important dataset, we have attempted to evaluate the quality of the data, especially in the light of the discussions in the early 1960s about the value of arsenic as a way of discriminating between authentic and inauthentic specimens. We tentatively support the observation that there is a significant difference between the arsenic data presented in the RLAHA and Freer gallery datasets. On the basis of a relatively crude comparison with other similar datasets, we suggest that the RLAHA data is more consistent with subsequent data, highlighting the fact that these data may still have some value for the study of Chinese bronzes. 


\section{Acknowledgements}

We obviously acknowledge the analysts in RLAHA in the late 1950s who carried out such a large and important volume of work. These are most likely to have been Audrey Blin-Stoyle, R.V. Jolowicz and C.C. Humphreys, supported by E.T. Hall. We also acknowledge the initiative given to the project given by William Watson at the British Museum, and the unnamed curators in the Ashmolean, Victoria and Albert and Cambridge Museums who must have assisted in the sampling programme. We are grateful to Drs Francis Schweizer and Peter Northover for rescuing the record cards and storing them, and to Cherry (Yingzi) Zhangsun and Gary (Yui-Kang) Hsu who assisted in their recovery.

\section{References}

Bagley, R.W. (1987). Catalogue of Shang ritual Bronzes in the Arthur M. Sackler Collections. Arthur M. Sackler Foundation, Washington D.C.

Barnard, N. (1961). Bronze Casting and Bronze Alloy in Ancient China. Monumenta Serica Monograph XIV. Australian National University and Monumenta Serica, Canberra.

Barnard, N. and Tamotsu, S. (1975). Metallurgical Remains of Ancient China. Nichiōsha, Tokyo.

Britton, D. and Richards, E.E. (1969). Optical emission spectroscopy and the study of metallurgy in the European Bronze Age. In Brothwell, D. and Higgs, E. (eds.) Science in Archaeology, Thames and Hudson, London, 603-613 ( $2^{\text {nd }}$ edition).

Brown, M.A. and Blin-Stoyle, A.E. (1959). A sample analysis of British Middle and Late Bronze Age material, using optical spectrometry. Proceedings of the Prehistoric Society 25, 188-208.

Garner, Sir H.M. (1962). Bronze casting and bronze alloy in ancient China. Oriental Art VIII 3738.

Gettens, R.J. (1969). The Freer Chinese Bronzes. Vol. II Technical Studies. Smithsonian Institution, Washington D.C.

Jolowicz, R.V. (1959). Spectrographic analyses of bronzes by a solution method. Archaeometry 2 (Supplement), 18-24.

Kaiser, H. (1941-44). Über die verschiedenen Verfahren zur Auswertung der Spektren bei quantitativen spektrochemischen Analysen. Spectrochimica Acta 2, 1-17.

Pope, J.A., Gettens, R.J., Cahill, J and Barnard N. (eds.). The Freer Chinese Bronzes. Vol. I Catalogue. Smithsonian Institution, Washington D.C. 
Rawson, J. (1990). Western Zhou Ritual Bronzes in the Arthur M. Sackler: Catalogue. Arthur M. Sackler Foundation, Washington D.C. 